\title{
Fear of crime and sense of security - on an example of polish youth
}

\author{
Marcin Pawełczyk \\ University of Silesia Katowice Poland
}

This presentation is going to present the results of scientific research about the fast-growing problem of crime - both in Poland and Europe, in minds of youth (represented by 1000 youngsters from youth demographic 16-26 years old living in Poland).

The project (official name translated from polish would be as following < however for the purpose of conference and presentation it has been changed for more suitable name>) that results will be presented is called "Safety and sense of security. Interdyscyplinarne criminological research of fear of crime among young people representing diverse environments" and has been created thanks to scientific grant of Silesia University Katowice. The research initiative represented sociological, psychological and law point of view.

The studied group was examined using authorial questionnaire, that has been made in cooperation with professors from faculty of sociology and psychology in Katowice, Poland. The questionnaire asked about several topics, mostly about fear of crime, fear of being a victim and determinants that could be the main reasons why specified unit of society feel specified fear. Those determinants were for example: Media, Police, vandalism, graffiti etc.

Questionnaire was build with VIII sections and 44 questions.

The demographic of the research was polish youth from 16-26 years old. Students and pupils representing different school's societies.

There have been 1000 participants that have been examined in the course of the research.

The project assumed measuring the amount of fear of crime with correlation to sense of security. It also analyzed commonly know definitions of fears, phobias etc. and upgraded them to modern needs of youth.

The research was held under the Law and Administration faculty, in the cathedral of criminal law and criminology under supervision of the head of the unit.

In the project, there have been used classical deviations theories created by Emilie Durkheim, anomie theory created by Robert King Merton - two of the finest sociologist in those matters. Also, the large comparison for the surveys results were "Polish Fear Research" (done every year by the polish police department) and the book "Fear of Crime. Empirical theoretical methodological study" by Pawel Ostaszewski

The presentation at the conference will show, deep statistical analysis of the questionnaire results and its influence on society with comparison on known knowledge in "fear of crime" sociological fields. It will also present the possible outcomes about the determinants that change the unit perspective about the crime, and the vulnerability of crime.

As the "fear of crime" and safety levels of unit are very important matter in sociology nowadays, mostly because of terrorism, immigrants, criminal politics etc. it is important that this topic is being tested more and more, especially in young demographics as their socialization process is getting drastically changed. And because of those changes there might occur much more mental disorders, deviations anomies etc. in the future, that society is not ready and prepared for.

Keywords: Crime, security, Fear of crime, sense of security, youth 